www.jmscr.igmpublication.org

Impact Factor 5.84

Index Copernicus Value: 83.27

ISSN (e)-2347-176x ISSN (p) 2455-0450

crossref DOI: _https://dx.doi.org/10.18535/jmscr/v5i5.186

Journal Of Medical Science And Clinical Research

\title{
A Study of incisional hernia repair at teaching tertiary care hospital - Laparoscopic vs. Open Repair
}

\author{
Authors \\ Dr Lalan Kumar ${ }^{1}$, Dr Manish ${ }^{2}$, Dr A.P. Singh ${ }^{3}$ \\ ${ }^{1}$ Assistant Professor, ${ }^{2}$ Associate Professor, ${ }^{3}$ Professor \\ Department of Surgery, Government Medical College, Bettiah, West Champaran, Bihar \\ Corresponding Author \\ Dr Lalan Kumar \\ Assistant Professor, Government Medical College Bettiah, West Champaran, Bihar \\ Email: lalanpmch@gmail.com
}

\begin{abstract}
Importance: Incisional hernia is the most frequent surgical complication after laparotomy. Up to $11-20 \%$ of all patients without wound complications develop an incisional hernia.

Objective: To compare laparoscopic vs. open ventral incisional hernia repair with regard to postoperative pain and nausea, operative results, perioperative and postoperative complications, hospital admission, and recurrence rate.

Design: All patients with incisional hernia attending this hospital between September 2013 to March 2016 with a follow up at least 12 months were included in this study.

Setting: All patients were operated at the teaching hospital associated with ours institution.

Participants: sixty patients were randomized equally to laparoscopic or open mesh repair. Patients with an incisional hernia larger than $3 \mathrm{~cm}$ and smaller than $10 \mathrm{~cm}$, either primary or recurrent, were included. Patients were excluded if they had an open abdomen treatment in their medical histories.

Intervention: Laparoscopic or open ventral incisional hernia repair.

Main Outcome Measures: The main outcome of the trial was postoperative pain. Secondary outcomes were use of analgesics, perioperative and postoperative complications, operative time, postoperative nausea, length of hospital stay, recurrence, morbidity, and mortality.

Results: Median blood loss during the operation was significantly less $(15 \mathrm{~mL} v \mathrm{v} .75 \mathrm{~mL} ; P=.05)$ as well as the number of patients receiving a wound drain (7\% vs. 59\%; P .001) in the laparoscopic group. Operative time for the laparoscopic group was longer (105 minutes vs. 78 minutes; $P=.001$ ). Perioperative complications were higher after laparoscopy (61\% vs. 47\%). Visual analog scale scores for pain and nausea, completed before surgery and 3 days and 1 and 4 weeks postoperatively, showed no significant differences between the 2 groups. At a mean follow-up period of 28 months, a recurrence rate of $9 \%$ was reported in the open group and 11\%, in the laparoscopic group $(P=.30)$. The size of the defect was found to be an independent predictor for recurrence $(P \quad .001)$.

Conclusions and Relevance: During the operation, there was less blood loss and less need for a wound drain in the laparoscopic group. However, operative time was longer during laparoscopy. Perioperative complications were higher in the laparoscopic group. Visual analog scores for pain and nausea did not differ between groups. The incidence of a recurrence was similar in both groups. The size of the defect was found to be an independent factor for recurrence of an incisional hernia.
\end{abstract}




\section{Introduction}

Incisional Hernia is The Most Frequent surgical complication after laparotomy. Up to $11-20 \%$ of all patients without wound complications develop an incisional hernia. ${ }^{25}$ This is associated with discomfort, pain, respiratory restriction, and dissatisfactory cosmetic results.1-6 The associated morbidity often results in subsequent hernia repair. $^{7,8}$

Although significant improvements have been achieved in the field of incisional hernia concerning operative technique and the use of prosthetic materials, recurrence rates remain high at $32 \%$ to $63 \% .^{9}$ Risk factors associated with recurrence, such as hernia size, unfortunately cannot be influenced.10 The quest for more effective and less invasive techniques continues.

The introduction of minimally invasive surgery in the early 1990s enabled the possibility of laparoscopic incisional hernia repair. ${ }^{11}$ laphas proved to be a safe, effective, efficient, and less painful technique for many types of surgery and has become the current "gold standard" for cholecystectomy. ${ }^{12}$ Laparoscopic incisional hernia repair is a widely used and accepted operative technique, assuming general advances of laparoscopy are also valid for this group. Recent studies have shown that in the short term, laparoscopic repair is superior to open repair in terms of less blood loss, fewer perioperative complications, and shorter hospital stay. ${ }^{13,14}$ Longterm outcomes such as recurrence rates for laparoscopic mesh repair are in the range of 9 to $12 \% .^{25}$

The aim of this study was to compare laparoscopic vs. open ventral incisional hernia repair with regard to postoperative pain and nausea, operative time, blood loss, perioperative and postoperative complications, length of hospital stay, and recurrence rates.

\section{Material and Methods}

All patients with incisional hernia attending this hospital between September 2013 to march 2016 were included in this study. Inclusion criteria were hernia diameter between 3 and $10 \mathrm{~cm}$, location at the ventral abdominal wall at least $5 \mathrm{~cm}$ from the costae and inguinal area, indication for elective repair, age 18 years or older, and written informed consent. Exclusion criteria included a contraindication for pneumoperitoneum, an absolute contraindication for general anesthesia.

After obtaining informed consent, patients were randomized by computer-generated lists. Patients and medical staff were not blinded to the allocated procedure.

\section{Laparoscopic Incisional Hernia Repair}

Laparoscopic incisional hernia repair was performed through 3 to 5 abdominal trocars (one $10 \mathrm{~mm}$ and 2 to four $5 \mathrm{~mm}$ ). Pneumo- peritoneum was achieved by Veress needle or open introduction of a blunt-tip trocar for inflation with carbon dioxide to achieve intra-abdominal pressure up to $15 \mathrm{~mm} \mathrm{Hg}$. A 300 laparoscope was used to provide a view of the inner surface of the abdominal wall. The additional 5-mm trocars were positioned at the opposite site of the hernia. The hernia port size was measured. Extensive adhesiolysis was performed if necessary using diathermy. The omentum and bowel were detached from the abdominal wall to expose the hernial defect. The hernia sac was not dissected. The mesh was introduced into the abdominal cavity through the $10-\mathrm{mm}$ trocar. The mesh was then placed over the defect with at least $5-\mathrm{cm}$ overlap at all sides. Fixation of the mesh was achieved by $5-\mathrm{mm}$ nonabsorbable tackers. A concentric ring of tackers was placed in the peripheral margin of the mesh. Transfascial sutures were often used for mesh positioning and supplementary fixation. Hemostasis was achieved before removal of the trocars. All 10-mm trocar fascial defects were closed. Skin defects were closed with absorbable monofilament sutures.

\section{Open Incisional Hernia Repair}

Incisions were made in the old scar depending on the localization and size of the hernia. The subcutaneous layer and scar tissue were dissected from the abdominal wall to identify and expose 
the hernia sac. The hernia port size was measured. Dissection of the hernia sac from beneath the rectus muscles was performed if possible. Opening and resection of the hernia sac was avoided. Whenever possible, the posterior rectus sheath or peritoneum was dissected from the rectus muscles. After closing of the peritoneum or posterior rectus sheath, a mesh was positioned preperitoneally or in the sublay position, respectively, with at least 5 -cm overlap at all sides. The mesh was fixated to the rectus muscle at each corner and side with nonabsorbable (polypropylene) sutures. The anterior rectus sheath was closed only if tension-free repair was possible. The use of wound drainage was not protocolized for the study. Subcutaneous drains with low-vacuum closed systems were placed in case of large dissection areas. The skin was closed with mono- filament absorbable sutures or staples.

\section{Postoperative Care}

After the operation, patients were transported to the surgical ward. Patients in whom extubation was not possible were ad- mitted to the intensive care unit for observation and ventilatory support. Postoperative analgesia consisted of paracetamol and nonsteroidal anti-inflammatory drugs or intravenous analgesics if necessary. Patients were discharged from the hospital when they mobilized autonomously.

\section{Primary and Secondary Outcomes}

The primary outcome of the trial was postoperative pain. Secondary outcomes were use of analgesics, perioperative and post- operative complications, operative time, postoperative nausea, length of hospital stay, recurrence, morbidity, and mortality.

\section{Follow-Up Evaluation}

Preoperatively, patients were asked to complete visual analog scales for pain and nausea. Followup visual analog scales were completed at 3 days, 1 week, and 4 weeks postoperatively. After discharge from the hospital, patients were invited for follow-up visits at outpatient clinics at 1 week, 6 weeks, then annually.

\section{Statistical Analyses}

All patient data were analyzed on an intention-totreat basis. Time until recurrence was evaluated using Kaplan-Meier curves and the log-rank test. Pain and nausea visual analog scale scores were compared with repeated-measures analysis of variance. Other continuous variables were compared using an independent-samples t test or Mann-Whitney test in cases of non-normal distribution.

Statistical analysis was performed using SPSS (IBM SPSS).

P .05 (2-tailed) was considered significant.

\section{Result}

Between September 2013 and march 2016, 60 patients were randomly assigned to undergo either laparoscopic $(n=28)$ or open $(n=32)$ incisional hernia repair. The 2 groups were similar in age, sex ratio, mean body mass index, hernia size, and preoperative co morbidity (Table 1).. In total, 60 patients were included for analysis (Figure 1).

Table-1: Patient Characteristics

\begin{tabular}{|c|c|c|c|}
\hline \multirow[b]{2}{*}{ Characteristic } & \multicolumn{3}{|c|}{ Total No.(60) } \\
\hline & $\begin{array}{l}\text { Open } \\
(\mathbf{n}=32)\end{array}$ & $\begin{array}{l}\text { Lapaoscopic } \\
(\mathbf{n}=\mathbf{2 8})\end{array}$ & $\begin{array}{l}P \\
\text { Value }\end{array}$ \\
\hline Fem ale & $26(81.2)$ & $23(82.1)$ & .82 \\
\hline Age, $y \cdot \operatorname{mean}(S D)$ & $48(12.8)$ & $46(12.8)$ & .86 \\
\hline Preoperative BMI, mean (SD) & $27.2(4.6)$ & $28.3(4.7)$ & .80 \\
\hline Rimay incisional hernia & $26(81.25)$ & $22(78.5)$ & .25 \\
\hline Recurrent incisional hernia & $6(18.75)$ & $6(21.5)$ & .42 \\
\hline Hernia diam eter, $\mathrm{cm}$, median (IQR) & $5(4-10)$ & $5(48)$ & .43 \\
\hline
\end{tabular}

Figure-1: Flowchart of Patient in the study

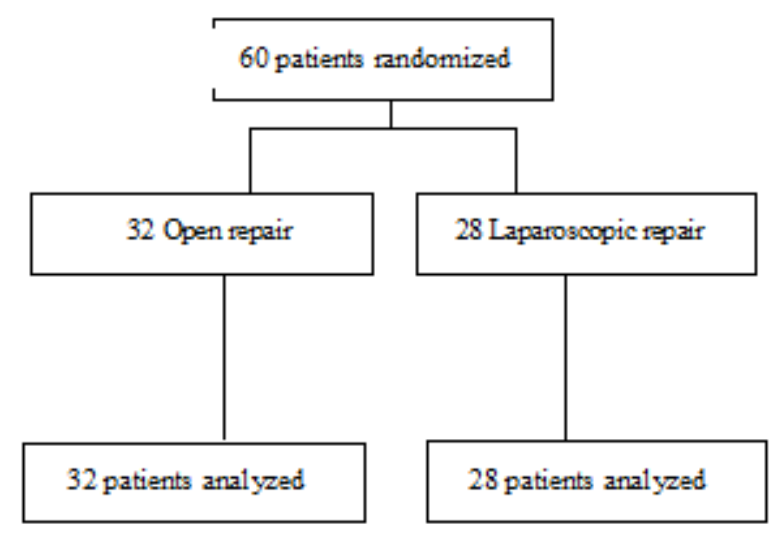




\section{Operative Results}

Operative data for both groups are shown in Table 2. The mean operative time in the laparoscopic group was significantly longer than in the open group (105 minutes vs 78 minutes; $\mathrm{P}=.001$ ). In the laparoscopic group, 2 of the 28 patients $(7.1 \%)$ required conversion to open repair because of technical reasons. The estimated blood loss was significantly higher in the open group compared with the laparoscopic group (median, $75 \mathrm{~mL}$ vs 15 $\mathrm{mL} ; \mathrm{P}=.05$ ). None of the patients required blood transfusion. Closed suction drains were placed subcutaneously in 19 patients in the open group and in the abdominal cavity in 2 patients in the laparoscopic group (P .001). The overall perioperative complication rate for laparoscopic repair $(10 \%)$ was higher than open repair $(3 \%)(\mathrm{P}$ $=.049)$. The operative complications included enterotomy, serosal bowel injury, and bladder perforation. Postoperative complications occurred more often in the laparoscopic group; however, the difference in postoperative complications was not significant (58\% vs. $48 \%$; $\mathrm{P}=.13$ ). Important postoperative complications in both groups were hematomas, wound infections, airway infections, and urinary tract infections (Table 3). Preoperative measured hernia size was equal in both groups (median, $5 \mathrm{~cm}$ [IQR, $4-10 \mathrm{~cm}$ ] in the open group vs $5 \mathrm{~cm}$ [IQR, 4-8 cm] in the laparoscopic group; $\mathrm{P}=.44$ ).

\section{Postoperative Pain and Nausea}

There were no significant differences in preoperative and postoperative pain scores (Figure 2). During 4 weeks of follow-up, pain scores were similar. At the 4-week follow- up, 7 patients (25\%) in the laparoscopic group and 8 patients (25\%) in the open group reported persisting pain, requiring prolonged analgesia use $(\mathrm{P}=.54)$. Visual analog scale scores for nausea were also comparable for both groups.
Table-2: Perioperative Outcomes

$\begin{array}{lccr} & \text { Open } & \text { Laparoscopic } & \text { P } \\ \text { Results } & \mathrm{n}=32) & \mathrm{n}=28) & \text { Value } \\ \text { Operative lime, min mazn (SD) } & 78(33) & 105(49) & .001 \\ \text { Estinatei bloodloss,mL. median (QR) } & 75(10-100) & 15(1-40) & .05 \\ \text { Conversion. Na (\%) } & & 2(7 \%) & \\ \text { Waurd dain No.(\%) } & 19(59 \%) & 2(7 \%) & .001 \\ \text { Lenght of hospital stay, d, } & 3(2-5) & 3(2-5) & 0.5\end{array}$

Table-3 Intraoperative and Postoperative Complication

\begin{tabular}{|c|c|c|c|}
\hline \multirow[t]{2}{*}{ No of complication } & \multicolumn{2}{|c|}{ No. ofPaients } & \multirow[b]{2}{*}{$\begin{array}{c}P \\
\text { Value }\end{array}$} \\
\hline & $\begin{array}{l}\text { Open } \\
(n=32)\end{array}$ & $\begin{array}{l}\text { Laparoscopic (n } \\
=28)\end{array}$ & \\
\hline Intraooerative complications & $1(3)$ & $3(10)$ & .049 \\
\hline Serosal bowel injury & 0 & $1(3.5)$ & \\
\hline Enterotom $\mathrm{v}$ & $1(3.1)$ & $1(3.5)$ & \\
\hline Uninary bladder perforaton & 0 & $1(3.5)$ & \\
\hline Postoperative complications & $14(43)$ & $14(50)$ & .13 \\
\hline Wound infection & $2(6.2)$ & $1(3.5)$ & \\
\hline $\begin{array}{l}\text { Wound dehisœenœ } \\
\text { Fascia dehiscence }\end{array}$ & $\begin{array}{l}1(3) \\
1(3)\end{array}$ & $\begin{array}{l}0 \\
0\end{array}$ & \\
\hline Hem atom a & $3(9.3)$ & $3(10.5)$ & \\
\hline Seroma & $1(3)$ & $2(7)$ & \\
\hline Severe pan & $1(3.1)$ & $1(3.5)$ & \\
\hline Airway infection & $1(3.1)$ & $1(3.5)$ & \\
\hline Urinary tract infection & $1(3.1)$ & $1(3.5)$ & \\
\hline Phlebitis & $2(6.2)$ & $1(3.5)$ & \\
\hline Ileus & 0 & $1(3.5)$ & \\
\hline Postoperative bleeding & $1(3.1)$ & $2(7)$ & \\
\hline Relaoarotomv & $0(3.1)$ & $2(7)$ & \\
\hline
\end{tabular}

\section{Follow-Up/Recurrence}

At a mean follow-up of 28 months after index surgery, 45 of 60 patients $(75 \%)$ completed follow-up (Figure 3). Patients were examined at the out- patient clinic for the presence of incisional hernia in standing and decubitus positions. In case of doubt, ultra- sonography or computed tomography scan was performed. The recurrence rates was $10 \%(n=6)$. There is no difference in recurrence rate between open vs laparoscopic incisional hernia repair. Recurrence rates in the different hospitals ranged from $0 \%$ $33 \%$ There was no significant difference between centers regarding recurrence rates.

Figure-2

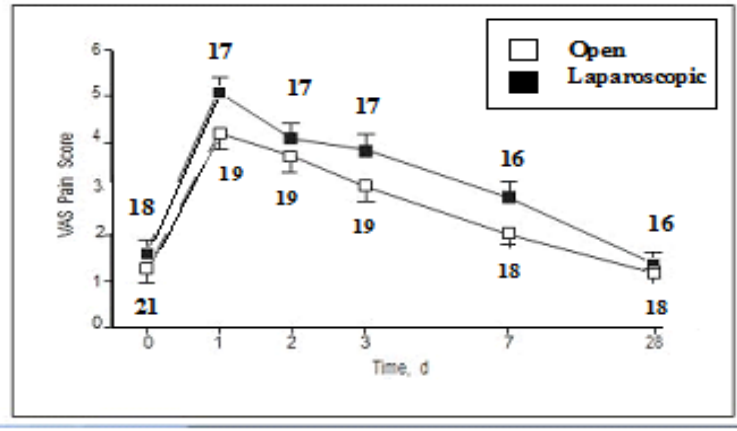


Visual analog scale (VAS) scores postoperative pain. The numbers that are reported in the figure indicate the number of patients evaluated at the different times. The error bars represent standard errors.

\section{Table -3}

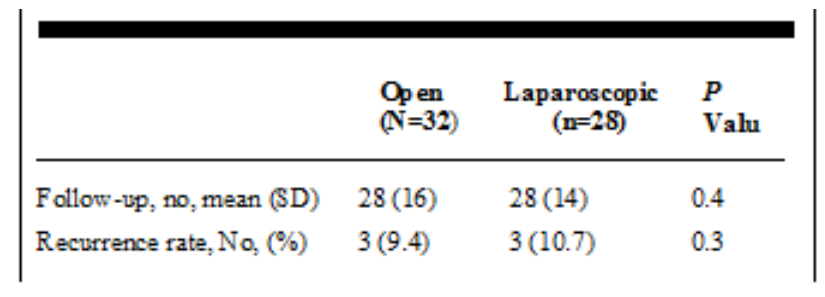

\section{Discussion}

This study is not the first evaluation of the value of laparoscopic incisional hernia repair. In our study, laparoscopic incisional hernia repair was not associated with less postoperative pain and nausea compared with open incisional hernia repair. The operative time was significantly longer for laparoscopic repair. Also, perioperative complications were higher in the laparoscopic group. During a median follow-up period of 28months, recurrence rates were comparable. Hernia size was, as previously reported, positively correlated with recurrence rates $(\mathrm{P}=$ .01). ${ }^{10}$ The basic techniques of laparoscopic incisional hernia repair have not been subject to major changes since their introduction in the early 1990s. ${ }^{11}$ Prospective studies on operative and long-term results have led to improvement of techniques and implant materials. For example, after Halm et al ${ }^{16}$ reported high rates of adhesions and bowel resection associated with intraperitoneal use of polypropylene mesh, use of this technique became obsolete. Meanwhile, significant improvements have been achieved in research and development of less adhesive prosthetic materials.

For open incisional hernia repair, sufficient evidence exists to support the superiority of mesh repair over suture repair in terms of recurrences. ${ }^{9,17}$ Polypropylene is the most widely used material for open mesh repair and is most often placed in the sublay (retromuscular) position. ${ }^{18}$ A recent Cochrane review, however, yielded in- sufficient evidence as to which type of mesh or which mesh position (onlay or sublay) should be used. ${ }^{19}$ In the underlying trial, the use of mesh was mandatory for all incisional hernia repairs, frequently using polypropyl- ene material in the sublay or intraperitoneal position.

Shorter operative time for laparoscopic incisional hernia repair was reported by a number of recently published studies, ${ }^{13,14,20,21}$ while other studies show no differences or longer operative times in the laparoscopic group. ${ }^{22,23}$ In small incisional hernia, introduction of trocars and positioning of instruments can be time-consuming. In the open technique, the hernia is often already reduced within this time. In the laparoscopic technique, the positioning and fixation of the mesh to the ventral abdominal wall can be time- consuming. A major factor that might have affected the operative time in the laparoscopic group was the extensive adhesiolysis in the midline of the abdominal wall. Adhesiolysis was necessary for positioning the mesh but also for observing any other small hernia or "Swiss-cheese" defects. A combination of these factors could possibly explain the significantly longer operative time in the laparoscopic group. One hundred minutes to perform a laparoscopic ventral incisional hernia repair, however, is reasonable and conforms to data from previous studies.

Several small randomized studies reported no differences in postoperative pain after laparoscopic and open incisional hernia repair. ${ }^{13,14,20}$ One trial reported reduced use of analgesics after laparoscopic repair. ${ }^{21}$ Postoperative pain after incisional hernia repair often originates not from the hernia itself, but from the surrounding tissues. Mesh fixation materials, eg, tackers or transfascial sutures, are believed to be responsible for postoperative pain. ${ }^{24}$ The ad- vantages of laparoscopy regarding surgical wounds and wound pain could possibly be offset by mesh fixation ma- terials such as tackers and transfascial sutures.

Several studies have shown a shorter length of hospital stay after laparoscopic incisional hernia 
repair (1.5 vs 3 days). ${ }^{13,14,20-22}$ After laparoscopic surgery, patients are expected to mobilize and recover faster. This, however, could not be confirmed by our data since length of hospital stay was comparable for both groups.

Previous studies have not shown significant differences in recurrence rates for laparoscopic and open incisional hernia repair. ${ }^{13,14,20-22}$ Contrary to previous studies that reported recurrence rates up to $20 \%$ with mesh repair, there are some studies showing exceptionally low recurrence rates varying between $0 \%$ and $5 \%{ }^{9,13,14}$ In this study, recurrence rates were found to be similar for both groups at an overall rate of $17 \%(14 \%$ vs $18 \% ; \mathrm{P}=.30)$. These relatively high recurrence rates, compared with recent studies, could possibly be explained by obligatory clinical examination of all patients included in our study. Likewise, patients who did not report any complaints or symptoms of possible recurrence by questionnaire were also invited to the outpatient department (OPD). Another explanation could possibly be the smaller numbers of included patients in previously conducted studies, resulting in exceptionally low recurrence rates due to chance.

Based on this large randomized clinical trial, laparoscopic incisional hernia repair is an effective technique with recurrence rates comparable with open repair. Preoperative complications, however, were significantly higher after laparoscopic repair. Common advantages of laparoscopic surgery, such as reduced amount of blood loss and less wound drainage, also applied for this study. Despite the statistical difference in blood loss between the 2 techniques, the clinical significance is negligible. Short-term benefits of laparoscopic incisional repair described in previous studies, eg, preoperative complications, operative time, and length of hospital stay, could not be confirmed. Long-term results and data on cost- effectiveness are necessary to make a more complete comparison between the 2 operative techniques

\section{Reference}

1. Sugerman HJ, Kellum JM Jr, Reines HD, DeMaria EJ, Newsome HH, Lowry JW. Greater risk of incisional hernia with morbidly obese than steroid-dependent patients and low recurrence with prefascial polypropylene mesh. Am J Surg. 1996; 171(1):80-84.

2. Fassiadis N, Roidl M, Hennig M, South LM, Andrews SM. Randomized clinical trial of vertical or transverse laparotomy for abdominal aortic aneurysm repair. $\mathrm{Br} \mathrm{J}$ Surg. 2005;92(10):1208-1211.

3. Lewis RT, Wiegand FM. Natural history of vertical abdominal parietal closure: Prolene versus Dexon. Can J Surg. 1989;32(3):196-200.

4. Mudge M, Hughes LE. Incisional hernia: a 10 year prospective study of inci- dence and attitudes. Br J Surg. 1985;72(1):70-71.

5. Raffetto JD, Cheung Y, Fisher JB, et al. Incision and abdominal wall hernias in patients with aneurysm or occlusive aortic disease. J Vasc Surg. 2003;37(6): 11501154.

6. Rodriguez HE, Matsumura JS, Morasch MD, Greenberg RK, Pearce WH. Abdominal wall hernias after open abdominal aortic aneurysm repair: prospective radiographic detection and clinical implications. Vasc Endovascular Surg. 2004; 38(3):237-240.

7. Ho “ er J, Lawong G, Klinge U, Schumpelick V. Factors influencing the develop- ment of incisional hernia: a retrospective study of 2,983 laparotomy patients over a period of 10 years [in German]. Chirurg. 2002;73(5):474-480.

8. Frijters D, Achterberg W, Hirdes JP, Fries BE, Morris JN, Steel K. Integrated health information system based on Resident Assessment Instruments [in Dutch]. Tijdschr Gerontol Geriatr.2001;32(1):8-16.

9. Burger JW, Luijendijk RW, Hop WC, Halm JA, Verdaasdonk EG, Jeekel J. 
Long- term follow-up of a randomized controlled trial of suture versus mesh repair of incisional hernia. Ann Surg. 2004;240(4):578-583, discussion 583-585.

10. Hesselink VJ, Luijendijk RW, de Wilt JH, Heide R, Jeekel J. An evaluation of risk fac- tors in incisional hernia recurrence. Surg Gynecol Obstet. 1993;176(3):228234.

11. LeBlanc KA, Booth WV. Laparoscopic repair of incisional abdominal hernias using expanded polytetrafluoroethylene: preliminary findings. Surg Laparosc Endosc. 1993;3(1):39-41.

12. Keus F, de Jong JA, Gooszen HG, van Laarhoven CJ. Laparoscopic versus open cholecystectomy for patients with symptomatic cholecystolithiasis. Cochrane Da- tabase Syst Rev. 2006;(4):CD006231.

13. Olmi S, Scaini A, Cesana GC, Erba L, Croce E. Laparoscopic versus open incisional hernia repair: an open randomized controlled study. Surg Endosc. 2007;21(4): 555-559.

14. Misra MC, Bansal VK, Kulkarni MP, Pawar DK. Comparison of laparoscopic and open repair of incisional and primary ventral hernia: results of a prospective ran- domized study. Surg Endosc. 2006;20(12):1839-1845.

15. Forbes SS, Eskicioglu C, McLeod RS, Okrainec A. Meta-analysis of randomized controlled trials comparing open and laparoscopic ventral and incisional hernia repair with mesh. $\mathrm{Br} J$ Surg. 2009;96(8):851-858.

16. Halm JA, de Wall LL, Steyerberg EW, Jeekel J, Lange JF. Intraperitoneal polypropylene mesh hernia repair complicates subsequent abdominal surgery. World J Surg. 2007;31(2):423-429, discussion 430.

17. Luijendijk RW, Hop WC, van den Tol $\mathrm{MP}$, et al. A comparison of suture repair with mesh repair for incisional hernia. $\mathrm{N}$ Engl J Med. 2000;343(6):392-398.

18. Schumpelick V, Klinge U, Junge K, Stumpf M. Incisional abdominal hernia: the open mesh repair. Langenbecks Arch Surg. 2004;389(1):1-5.

19. den Hartog D, Dur AH, Tuinebreijer WE, Kreis RW. Open surgical procedures for incisional hernias. Cochrane Database Syst Rev. 2008;(3):CD006438.

20. Carbajo MA, Mart'in del Olmo JC, Blanco JI, et al. Laparoscopic treatment vs open surgery in the solution of major incisional and abdominal wall hernias with mesh. Surg Endosc. 1999;13(3):250-252.

21. Navarra G, Musolino C, De Marco ML, Bartolotta M, Barbera A, Centorrino T. Retromuscular sutured incisional hernia repair: a randomized controlled trial to compare open and laparoscopic approach. Surg Laparosc Endosc Percutan Tech. 2007;17(2):86-90.

22. Barbaros U, Asoglu O, Seven R, et al. The comparison of laparoscopic and open ventral hernia repairs: a prospective randomized study. Hernia. 2007;11(1):51-56.

23. McGreevy JM, Goodney PP, Birkmeyer CM, Finlayson SR, Laycock WS, Birkmeyer JD. A prospective study comparing the complication rates between laparoscopic and open ventral hernia repairs. Surg Endosc. 2003;17(11):1778-1780.

24. Topart P, Vandenbroucke F, Lozac'h P. Tisseel versus tack staples as mesh fixation in totally extraperitoneal laparoscopic repair of groin hernias: a retrospec- tive analysis. Surg Endosc 2005;19(5):724-727

25. Andersen L, Klein et all - Incisional hernia after open versus laparoscopic sigmoid resection. Surg Endosc. 2008;22:2026-2029. 